\title{
Determinación de los factores que inciden en la cultura de donación de órganos y tejidos en el Hospital General de Teziutlán
}

\author{
Determination of the factors that affect the culture of organ \\ and tissue donation at the General Hospital of Teziutlán
}

\author{
Ana Karen Ruiz-Dionisio,* Rodolfo Celio-Murillo, ${ }^{\ddagger}$ Martha Elena Barrientos-Núñez ${ }^{\S}$ \\ * Médico pasante de servicio social. Benemérita Universidad Autónoma de Puebla, Complejo Regional Sur. Unidad de Trasplantes Puebla. \\ ₹ Pediatra, alergólogo e inmunólogo. Catedrático investigador de la Facultad de Medicina. Benemérita Universidad Autónoma de \\ Puebla, Complejo Regional Sur. Miembro del Comité Académico del Colegio de Pediatría del Estado de Puebla 2018-2020. \\ $\S$ Médico familiar. Responsable de la Unidad de Trasplantes Puebla.
}

\begin{abstract}
RESUMEN
Introducción: Actualmente, el trasplante de órganos y tejidos es una alternativa eficaz para el tratamiento de pacientes con disfunción de alguna parte de su cuerpo. Sin embargo, la negativa de la ciudadanía a la donación de entrañas y texturas biológicas constituye un problema sanitario que ocasiona un desequilibrio entre la oferta y la demanda de partes disponibles a fin de trasplantarse. Existen ciertos factores como el miedo, la ignorancia, prejuicios, motivos religiosos, falta de información, entre otros que desencadenan el rechazo al obsequio. Teziutlán es una pequeña ciudad localizada al noreste del estado de Puebla, ubicada entre la Sierra Norte del estado; el hospital general de la ciudad recibe habitantes de los municipios aledaños pertenecientes a dicha sierra de Puebla, siendo en su mayoría de origen rural, por lo que resulta conveniente evaluar la opinión de una localidad alejada de la zona metropolitana del estado. Objetivo: Medir de modo cualitativo las actitudes de los pobladores encuestados en la localidad de Teziutlán, buscando determinar cuáles son los factores que interfieren para una respuesta positiva o negativa al legado de productos orgánicos y tejidos. Material y métodos: Estudio prospectivo, observacional y descriptivo, efectuado mediante la aplicación de 400 encuestas a la población usuaria de la consulta
\end{abstract}

\begin{abstract}
Introduction: Currently, organ and tissue transplantation is an effective alternative for treating patients with certain dysfunctions. However, the population's refusal to donate entrails and tissues constitutes a health problem that causes an imbalance between the supply and demand for organs available for transplantation. Certain factors such as fear, ignorance, prejudice, religious motives, and lack of information, among others, trigger the rejection of the donation. Teziutlán is a small city situated in the northeast of the state of Puebla, located between the northern mountains of the state. The city's general hospital receives inhabitants from the neighboring municipalities belonging to the Sierra Norte de Puebla, a population primarily of rural origin, so it is convenient to evaluate the opinion from an area far from the state's metropolitan zone. Objective: To measure qualitatively the attitudes of the surveyed population to determine the factors that interfere with a positive or negative response to organ and tissue donation in the Teziutlán population. Material and methods: Prospective, observational, and descriptive study carried out by applying 400 surveys to the user population of the outpatient clinic of the General Hospital of Teziutlán Puebla. Results: It was found that $85 \%$ of the surveyed population approve of organ and tissue donation, although
\end{abstract}

Citar como: Ruiz-Dionisio AK, Celio-Murillo R, Barrientos-Núñez ME. Determinación de los factores que inciden en la cultura de donación de órganos y tejidos en el Hospital General de Teziutlán. Rev Mex Traspl. 2021; 10 (2): 51-57. https://dx.doi.org/10.35366/101411 
externa del Hospital General de Teziutlán Puebla (HGTP). Resultados: Se encontró que $85 \%$ de las personas encuestadas está a favor de la donación de piezas y lienzos biológicos, aunque sólo $67 \%$ estaría dispuesta a donar sus entrañas o tejidos después de la vida, y sólo $33 \%$ estaría dispuesto a regalar los órganos de algún pariente. Las principales causas por las que se manifiestan en contra de la cesión es por desconfianza del personal médico $(33 \%)$ y miedo al tráfico de partes orgánicas (27\%). Conclusión: En este estudio, la mayor parte de la gente está hipotéticamente en pro de la donación de sus entrañas; sin embargo, la intención real de convertirse en donador disminuye cuando se trata de obsequiar los órganos propios, y esta disposición disminuye aún más si se trata de donar los de un familiar. Es necesario dar mayor difusión del proceso de regalo y procuración de vísceras y tejidos, primero a la plantilla de salud, y desde luego también al público en general, proporcionando información real y confiable que muestren un proceso trasparente y legal para recuperar la confianza de la población.

Palabras clave: Donación de órganos, encuesta de opinión, actitudes sobre la donación de órganos.

\section{INTRODUCCIÓN}

El trasplante de órganos es uno de los grandes avances de la medicina y una esperanza de vida para pacientes con enfermedades terminales en distintas partes del cuerpo; sin embargo, aún existen barreras que dificultan el proceso de legado de aparatos orgánicos. La donación de entrañas, tejidos y células consiste en el consentimiento tácito o expreso de la persona de modo que, en vida o después de su muerte, su cuerpo o cualquiera de sus componentes se utilicen para trasplantes.

En este país, a pesar de los esfuerzos y programas de acción, la negación a la entrega de vísceras y texturas corporales constituye un problema social, que evoca varios mitos y creencias socioculturales. La principal problemática radica en la negativa familiar a la concesión de partes orgánicas. ${ }^{1-7} \mathrm{Si}$ bien la mayoría de la población se ha declarado a favor de la donación, en el momento de tomar una decisión la respuesta se torna negativa. ${ }^{8}$ Existen varios factores que influyen en la decisión de las personas a donar o no sus vísceras; entre los más mencionados se encuentran: el miedo, la ignorancia, prejuicios, nociones religiosas, falta de información, desconfianza del sistema, falta de empatía, variables relacionadas con el dialogo familiar, entre otros. ${ }^{9}$ Actualmente, en México, de acuerdo a las cifras del Centro Nacional de Transplantes (Cenatra), hay más de 22 mil pacientes en lista de espera que requieren de alguna only $67 \%$ were willing to donate their entrails or tissues after death, and only $33 \%$ were willing to donate those of a relative. The main reasons why they are against donation are mistrust of the doctor or medical personnel (33\%) and fear of organ trafficking (27\%). Conclusion: In this study, a large part of the population claims to be in favor of donation. However, the genuine disposition to become an actual donor diminishes when it comes to donating their own organs, and even more so if it is to donate those of a family member. It is necessary to make the organ and tissue donation and procurement process more widely known, first to health staff, and of course also to the general public to regain their confidence; accurate and reliable information that demonstrates a transparent and legal process.

Keywords: Organ donation, opinion poll, attitudes about organ donation.

pieza orgánica o tejido a fin de salvar su vida, o mejorar la calidad de ésta. Tristemente, en el país, la demanda de órganos y tejidos sobrepasa al número de donaciones, lo que crea un escenario poco alentador frente a la personas que esperan una oportunidad a través de un trasplante, los números no son halagüeños, y las cifras de receptores en espera aumentan año con año debido a la escasez de donaciones.

Se reconoce que la actitud, las creencias y el conocimiento de la gente acerca del tema son parte esencial del problema; por ello, se considera importante evaluar los factores que influyen, la percepción y disposición respecto a la donación de órganos en la localidad de Teziutlán, Puebla; región importante dentro de la Sierra Norte del estado. El hospital general de la ciudad recibe habitantes de los municipios aledaños pertenecientes a esa sierra, surgidos en su mayoría de origen rural, por lo que resulta conveniente evaluar la opinión de una ubicación alejada de la zona metropolitana del estado.

\section{MATERIAL Y MÉTODOS}

Trabajo revisado y aprobado por el Comité de Enseñanza e Investigación del HGTP. Se trata de un estudio prospectivo, observacional y descriptivo; efectuado mediante la aplicación de encuestas a los pobladores usuarios de la consulta externa del HGTP, el tamaño de la muestra se determinó para una confiabilidad de 
$95 \%$. Se aplicaron 400 encuestas a personas mayores de 18 años elegidas de manera aleatoria.

La encuesta consiste en un cuestionario impreso, de carácter voluntario y anónimo; fue elaborada con 25 preguntas de opción múltiple y dividida en cinco categorías:

I. Variables sociodemográficas (edad, sexo, escolaridad, religión y asentamiento).

II. Conocimientos en general sobre el tema de donación.

III. Actitud y opinión hacia la cesión de órganos y tejidos.

Tabla 1: Variables sociodemográficas de la población entrevistada.

\begin{tabular}{lc}
\hline & $\%$ \\
\hline Sexo & \\
Femenino & 55 \\
Masculino & 45 \\
Edad (años) & \\
18-24 & 40 \\
$25-34$ & 19 \\
$25-44$ & 18 \\
$>45$ & 23 \\
Religión & \\
Católica & 79 \\
Cristiana & 5 \\
Mormona & 3 \\
Pentecostés & 2 \\
Ninguna & 11 \\
Tipo de asentamiento & \\
Zona rural & 72 \\
Zona urbana & 28 \\
Escolaridad & \\
Ninguna & 3 \\
Primaria & 31 \\
Secundaria & 23 \\
Preparatoria & \\
Licenciatura & 14 \\
\hline
\end{tabular}

IV. Disposición real y acción realizada.

V. Impacto en la población.

\section{RESULTADOS}

\section{Variables sociodemográficas}

De las personas entrevistadas, $55 \%$ fueron mujeres y $45 \%$ hombres; los resultados de las variables sociodemográficas evaluadas se muestran en la Tabla 1. La religión que predominó fue la católica y el tipo de asentamiento que sobresalió fue la zona rural con $72 \%$. La distribución por edad, sexo y escolaridad se muestra en la Tabla 2. La parte gruesa de la ciudadanía joven se ubica en grados de escolaridad entre preparatoria y licenciatura; mientras que la población adulta en su mayoría se concentra en grados de escolaridad del nivel básico (primaria y secundaria). ${ }^{10}$

\section{Conocimientos generales sobre} donación de órganos y tejidos

El medio por el cual los entrevistados manifestaron haber recibido mayor información acerca del asunto fue a través de la televisión (50\%), seguidos de personal sanitario (26\%). Al evaluar el conocimiento del tema de donación de órganos en la gente, sólo $56 \%$ tenía comprensión del verdadero significado de muerte encefálica, y sólo $46 \%$ respondió correctamente que es necesario que el fallecimiento ocurra en un centro hospitalario a fin de poder efectuar la cesión. Hasta un $70 \%$ piensa que la edad y las enfermedades crónicodegenerativas (diabetes mellitus, hipertensión arterial, etcétera) son contraindicaciones para ser donador.

De ellos, $82 \%$ conocía acerca del legado de aparatos orgánicos, pero de la muestra total sólo 30\% sabía que debe comentarlo a su familia y sólo $25 \%$ conocía sobre la tarjeta de donador voluntario.

Tabla 2: Distribución de la población por edad, sexo y escolaridad.

\begin{tabular}{|c|c|c|c|c|c|c|c|c|}
\hline \multirow[b]{2}{*}{ Edad (años) } & \multicolumn{4}{|c|}{ Mujeres ( $\mathrm{N}=220$ ) } & \multicolumn{4}{|c|}{ Hombres $(N=180)$} \\
\hline & $18-24$ & $25-34$ & $35-44$ & $>45$ & $18-24$ & $25-34$ & $35-44$ & $>45$ \\
\hline \multicolumn{9}{|l|}{ Escolaridad } \\
\hline Ninguna & 0 & 0 & 8 & 4 & 0 & 0 & 0 & 0 \\
\hline Primaria & 8 & 8 & 16 & 32 & 12 & 12 & 12 & 24 \\
\hline Licenciatura & 20 & 0 & 4 & 4 & 8 & 12 & 4 & 4 \\
\hline
\end{tabular}


Tabla 3: Conocimientos generales sobre donación.

\section{$\%$}

$\begin{array}{lr}\text { ¿De qué medio proviene la información que usted conoce sobre } \\ \text { donación y trasplante de órganos y tejidos? } \\ \text { Televisión } \\ \text { Personal médico } & 50 \\ \text { Internet } & 26 \\ \text { Radio } & 16 \\ \text { Periódicos y revistas } & 6 \\ \text { ¿Cree usted que una persona con muerte encefálica? } & 2 \\ \text { Puede recuperarse y vivir normalmente } & 12 \\ \text { Es un estado de coma indefinido } & 32 \\ \text { Legal y médicamente ha fallecido y es el candidato ideal para } & 56 \\ \text { donar sus órganos }\end{array}$

Señale en cuál de las siguientes situaciones es posible

la donación de órganos:

Muerte en la vía pública

Muerte en terapia intensiva o dentro de un hospital

Muerte en el domicilio

Desconozco

$¿$ ¿Cree usted que alguna de las siguientes situaciones

impida ser donador de órganos y tejidos?

Personas mayores de 50 años

Personas con diabetes mellitus

Personas con hipertensión arterial

Todas las anteriores

Ninguna de las anteriores impide ser donador

¿Sabía usted que puede decidir sobre sus órganos

y tejidos en vida?

No lo sé

Sí lo sé

18

¿Sabe cómo puede convertirse o registrarse como donante

de órganos y tejidos si lo desea?

Con una tarjeta de donador voluntario

Con la licencia de conducir

Registro en internet en páginas oficiales

Informar a mi familia, pues ellos serán los responsables después

de mi muerte

No lo sé

50

26

16

6

2

12

32

56

Señale los órganos y tejidos que sabe se pueden

donar y trasplantar

Corazón

Riñones

Hígado

Pulmones

Páncreas

Intestino

Todos los anteriores

Córneas

Piel

Músculo

Huesos

Ligamentos y tendones

Válvulas cardiacas

Ninguno de los anteriores
En torno al conocimiento acerca de las partes y texturas corporales que se pueden obsequiar y trasplantar, los más conocidos son corazón y riñón (ambos con $90 \%$ de la muestra), y los menos conocidos son intestino y válvulas cardiacas (con 20 y 12\% respectivamente), $2 \%$ manifestó no conocer ningún órgano o tejido que se pueda donar (Tabla 3).

\section{Actitud y opinión hacia la donación} de órganos y tejidos

De los encuestados se declaró en pro de la donación; sin embargo, al evaluar la disponibilidad personal efectiva sólo $67 \%$ está dispuesto a regalar sus órganos y tejidos tras su fallecimiento, $6 \%$ no lo haría y los indecisos aumentaron a $27 \%$; la disponibilidad a donar disminuye aún más cuando se trata de un familiar, pues sólo 33\% está decidido a obsequiar las entrañas y tejidos de un familiar, la negativa aumentó hasta $21 \%$ y los indecisos a $46 \%$. Al cuestionar qué piezas orgánicas y sustancias biológicas concedería, la parte que la mayoría está dispuesto a ofrendar es el corazón (65\%), y lo que menos están inclinados a ceder son válvulas cardiacas (24\%). La principal razón por la que se manifiestan a favor de cederlas es para ayudar a otros a vivir (58\%). En contraste, las dos causas primoradiales por las que se manifiestan en contra de la donación son por desconfianza de la plantilla médica $(33 \%)$ y por temor al tráfico de órganos (27\%).

Por otro lado, al cuestionar acerca de la razón por la que no desean legar los órganos propios, la respuesta de la mayoría es que no manifiestan una negativa absoluta y en realidad si les gustaría donar, pero piensan que sus entrañas o tejidos no son aptos para hacerlo por padecer alguna enfermedad crónico-degenerativa o por ser de edad avanzada, por lo que automáticamente se autodescartan como donantes.

Dentro de las razones causales de no convidar las partes orgánicas de algún consanguíneo, 66 \% respondió que es por desconocer la decisión de su familiar, y sólo $10 \%$ expresó que su familiar manifestó previamen-

Tabla 4: Causas de negativa a donar órganos de familiares.

\begin{tabular}{lr}
\hline & $\%$ \\
\hline Porque desconozco la decisión de mi familiar & 66 \\
Pienso que no me corresponde la decisión & 20 \\
Porque el proceso retrasa la entrega del cuerpo & 0 \\
Porque mi familiar ya expresó que no quiere donar sus órganos & 10 \\
Por no poder conocer al receptor del órgano & 4
\end{tabular}


Tabla 5: Actitud y opinión a la donación.

\begin{tabular}{|c|c|}
\hline & $\%$ \\
\hline \multicolumn{2}{|l|}{ ¿Usted está en contra o a favor de la donación de órganos y tejidos? } \\
\hline A favor & 85 \\
\hline En contra & 2 \\
\hline Indeciso & 13 \\
\hline \multicolumn{2}{|l|}{ Razón por la que está a favor de la donación } \\
\hline Para ayudar a otros a vivir & 58 \\
\hline Porque si yo necesitara me gustaría que alguien me donara & 33 \\
\hline Porque tengo familiares 0 amigos que esperan un órgano & 9 \\
\hline Trascender después de la vida & 0 \\
\hline \multicolumn{2}{|l|}{ Razón por la que está en contra de la donación } \\
\hline Porque un ser querido ya falleció esperando un órgano & 7 \\
\hline Por motivos religiosos & 13 \\
\hline Porque pienso que hay tráfico de órganos & 27 \\
\hline Porque creo que el cuerpo debe permanecer completo & 13 \\
\hline Porque creo que las listas de espera no se respetan & 7 \\
\hline Por desconfianza del personal médico & 33 \\
\hline \multicolumn{2}{|l|}{ ¿Usted donaría sus órganos y tejidos después de morir? } \\
\hline Sí & 67 \\
\hline No & 6 \\
\hline Indeciso & 27 \\
\hline \multicolumn{2}{|l|}{$\begin{array}{l}\text { Si la respuesta fue negativa, ¿cuál es su razón personal para no } \\
\text { donar? }\end{array}$} \\
\hline $\begin{array}{l}\text { Sí me gustaría, pero creo que mis órganos no son aptos para } \\
\text { donarse }\end{array}$ & 34 \\
\hline Tengo miedo a que me dejen morir si saben que doy donador & 24 \\
\hline Quiero que mi cuerpo permanezca completo & 9 \\
\hline Desconfianza del sistema médico & 9 \\
\hline Por motivos religiosos & 12 \\
\hline Falta de información sobre el proceso & 12 \\
\hline \multicolumn{2}{|l|}{$\begin{array}{l}\text { ¿Usted donaría los órganos y tejidos de algún familiar que haya } \\
\text { fallecido? }\end{array}$} \\
\hline Sí & 33 \\
\hline No & 21 \\
\hline Indeciso & 46 \\
\hline \multicolumn{2}{|l|}{ ¿Por qué no donaría los órganos de algún familiar? } \\
\hline Porque desconozco la decisión de mi familiar & 66 \\
\hline Pienso que no me corresponde la decisión & 20 \\
\hline Porque el proceso retrasa la entrega del cuerpo & 0 \\
\hline Porque mi familiar ya expresó que no quiere donar sus órganos & 10 \\
\hline Por no poder conocer al receptor del órgano & 4 \\
\hline \multicolumn{2}{|l|}{ Si le gustaría donar, ¿qué órganos y tejidos está dispuesto a donar? } \\
\hline Corazón & 65 \\
\hline Riñones & 62 \\
\hline Hígado & 50 \\
\hline Pulmones & 42 \\
\hline Páncreas & 34 \\
\hline Intestino & 29 \\
\hline Córneas & 49 \\
\hline Piel & 34 \\
\hline Músculo & 30 \\
\hline Huesos & 28 \\
\hline Ligamentos y tendones & 30 \\
\hline Válvulas cardiacas & 24 \\
\hline
\end{tabular}

te su negativa a la donación (Tabla 4). Las causas de negativas se desglosan completamente en la Tabla 5.

\section{Disponibilidad personal real a la donación de órganos}

Sólo $47 \%$ de los encuestados manifestó que en su familia se ventila el tema de donación de órganos; y aunque la mayoría se expresó a favor de tal donación, la disposición real se evaluó con acciones realizadas para convertirse en donador, de los cuales $62 \%$ no ha realizado acción alguna hacia convertirse en donador, sólo $34 \%$ lo ha comunicado a su familia y $4 \%$ ha firmado tarjeta de donador voluntario (Tabla 6).

\section{Impacto en la población}

En general, se considera que el impacto que provocó el cuestionario en las personas entrevistadas fue positivo. Hasta $67 \%$ respondió que hablar acerca del tema de este obsequio le provoca un sentimiento de solidaridad y amor; al cuestionar si tras leer la encuesta, hablarán con su familia sobre el asunto y le expresarán su decisión, el 92 \% respondió afirmativamente. $Y$ finalmente, al cuestionar si ellos estuvieran en la situación de necesitar un órgano, 93 \% respondió que le gustaría recibirlo a través de ese regalo (Tabla 7).

\section{DISCUSIÓN}

El estudio reveló que la mayor parte de la población se inclina hacia la donación de órganos pues $85 \%$ expresó una respuesta favorable; sin embargo, la disponibilidad personal a convertirse en donador disminuye a $67 \%$, resultados similares se han descrito en estudios anteriores. ${ }^{8,9,11-13}$ La disposición a donar las vísceras de un familiar disminuye considerablemente hasta un $33 \%$, un decremento significativo comparado con el punto anterior.

Las causas vitales por las que se manifestaron en contra de la entrega son la desconfianza al personal del hospital y temor al tráfico de vísceras. Por otro lado, un punto importante que revela el estudio es que una de las principales causas de negativa personal a regalar los propios es que presuntamente no manifiestan negación absoluta, más bien se ven afectados por la creencia de que sus vísceras no son aptas para donarse y trasplantarse debido a situaciones como la edad o diversas enfermedades que en realidad no impiden ser donador; luego, automáticamente se autodescartan como donantes siendo este hecho responsable de gran parte de la negativa a la donación de órganos en 
esta población. Otra causa importante es el temor a no ser salvado en un centro hospitalario al notar que son donantes.

Una parte de los encuestados también marca como razón de negativa la falta de información en torno al proceso, lo que se ve reflejado en los resultados del conocimiento relativo al tema.

Es destacable que la comprensión y entendimiento del concepto de deceso encefálico es vital para la aceptación de la muerte, y facilitar la obtención de respuestas positivas a la transferencia, y tristemente, en este estudio sólo $56 \%$ entiende el concepto real de muerte cerebral. Resulta preocupante que un número considerable declaró haber recibido la información por parte del personal santiario, lo que denota la importancia de la correcta capacitación del personal de la salud acerca de la cuestión. Numerosos estudios han revelado que cuanto más se informa a la población sobre los diversos aspectos de la donación de órganos, tanto médicos como legales, hay mayor aceptación a la herencia de los tejidos propios o los de un pariente cercano. ${ }^{14-23}$

Otro factor que influye considerablemente es la falta de comunicación familiar referente al tema, pues sólo $34 \%$ ha informado a su familia su decisión de ser donador, hecho que toma importancia si se toma en cuenta que, según los resultados, la principal causa de negativa a donar vísceras de un consanguíneo es por desconocer su decisión (66 \%); además, sólo $4 \%$ ha firmado una tarjeta de donador espontáneo.

Como es de esperarse, la parte principal de la gente está inclinada a recibir un órgano o tejido en caso de necesitarlo, cifra que contrasta significativamente con la disponibilidad a obsequiar entrañas por parte de la población, parece que uno está inclinado a que la gente done sus vísceras después de la muerte, siempre y cuando no sean los propios o de algún pariente, como han registrado otros artículos previos. ${ }^{24}$

Tabla 6: Disponibilidad real y acciones realizadas.

\begin{tabular}{lc}
\hline & $\%$ \\
\hline ¿Alguna vez han hablado en familia sobre el tema de \\
donación de órganos? \\
Sí \\
No \\
Si usted ha pensado en donar, ¿qué ha hecho al respecto \\
para ser donador? \\
$\quad$ Firmar tarjeta de donador voluntario \\
Comentarlo con mi familia y pedir que respeten mi decisión \\
No he hecho nada al respecto \\
\end{tabular}

Tabla 7: Impacto en la población.

\begin{tabular}{lc}
\hline & $\%$ \\
\hline ¿Qué sentimiento causa en usted hablar sobre donación de órganos? & \\
Solidaridad y amor & 67 \\
Miedo & 11 \\
Tristeza & 10 \\
Enojo & 0 \\
No me provoca ningún sentimiento & 12 \\
Si su vida dependiera de ello, ¿estaría dispuesto a recibir un órgano? & \\
Sí & 93 \\
No & 7 \\
Después de leer esta encuesta, ¿se tomará un tiempo para & \\
dialogar con su familia acerca del tema? & \\
Sí & 92 \\
No & 8 \\
\hline
\end{tabular}

Por último, al evaluar el impacto causado en las personas entrevistadas, los resultados son alentadores al exhibir que $92 \%$ se declaró dispuesto a hablar sobre el asunto con su familia.

\section{CONCLUSIÓN}

En este estudio, la parte principal de los habitantes está en pro de la donación de órganos; sin embargo, la disposición real a convertirse en donador disminuye cuando se trata de conceder los propios, y ésta disminuye todavía más si se trata de donar los de un familiar.

La principal problemática radica en la falta de información verídica y real, y en la falta de comunicación relativa a este tema en el ambiente familiar, así como la desconfianza del sistema de salud y personal médico, lo cual no es raro, si se toma en cuenta que la zona de estudio está localizada en la Sierra Norte del estado. Es imprescindible que el personal de la salud recupere la confianza perdida de la ciudadanía general, como un paso esencial intentando lograr respuestas positivas en torno a la población.

Hace falta mayor difusión del proceso de herencia y procuración de aparatos orgánicos y tejidos, primero al personal de salud, mediante trípticos, cursos y conferencias sobre la cuestión; y desde luego también al público en general proporcionando información real y confiable, utilizando todos los medios de comunicación que se tienen al alcance. La difusión de la información por parte del equipo médico debe iniciar desde el primer nivel de atención. Resulta necesario que el concepto de muerte cerebral sea conocido universalmente, ya que es imprescindible para una mayor 
aceptación de la muerte y el legado orgánico. Iniciar la educación acerca de la donación desde la infancia puede ser una herramienta eficaz a fin de educar a las nuevas generaciones y así corregir la falta de información y las dudas entre las familias de los niños.

Por último, es importante promover el abordaje del tema en el núcleo familiar, concientizándolos en la decisión de convertirse en donador después de la muerte y promover el respeto a las decisiones de los familiares. Una herramienta que se puede usar a favor es promover el mensaje de amor y solidaridad que implica la donación de órganos y como ésta ayuda a otras personas. ${ }^{25-30}$

\section{REFERENCIAS}

1. Ley general de salud-título XIV-Donación, trasplantes y pérdida de la vida. [Consulta 25 septiembre 2019] Disponible en: http:// www.salud.gob.mx/unidades/cdi/legis/lgs/index-t14.htm

2. Reglamento de la Ley General de Salud en materia de trasplante. [Consulta 25 septiembre 2019] Disponible en: http:// www.diputados.gob.mx/LeyesBiblio/regley/Reg_LGS_MT.pdf.

3. Sistema Informático del Registro Nacional de Trasplante Corte al 03 de octubre de 2019. [Consulta 29 octubre 2019] Disponible en: https://www.gob.mx/cms/uploads/attachment/file/427652/ Presentacion_anual_2018.pdf

4. Secretaría de Salud, Centro Nacional de Trasplantes. [Consulta octubre 2019] Disponible en: http://cenatra.salud.gob.mx/ transparencia/trasplante_estadisticas.html

5. Nota de Prensa. Ministerio de sanidad, consumo y bienestar social. 2018. [Consulta octubre 2019] Disponible en: http:// www.ont.es/prensa/NotasDePrensa/2018 \%2008 \%2029 \%20 \%20DATOS \%20REGISTRO \%20MUNDIAL \%20DE \%20 TRASPLANTES.pdf

6. Zamora TAI, Díaz BY. Factores que inciden en la cultura de donación de órganos en Morelia, Michoacán: hacia una propuesta de política pública. Tla-melaua. 2018; 12 (44): 98119.

7. Ynglanda FD, Gustafsson M. Conocimientos, representaciones y comportamientos de la población de Laboulaye ante la donación de órganos. Universidad Abierta Interamericana, Sede Regional Rosario. 2014.

8. Guerra-Sáenz EK, Narváez-Navarro AG, Hernández-López AC, Bello SJ, Ruiz-Cantú G, Cordero-Pérez P, Zapata-Chavira H. Actitud hacia la donación y el trasplante de órganos y tejidos de tres instituciones de salud. Gaceta Médica de México. 2016; 152 (5): 688-696.

9. Arias TTM, Rodríguez WFL, de Pablo PAS, Patiño MAG, Balbuena MMM, Reyes PAS. Encuesta de opinión sobre donación de órganos 2009. Medicina Interna de México. 2010; 26 (4): 313-318.

10. Esparza OA, Quiñones J, Carrillo IC, Montañez P. Relación entre donación de órganos y los cinco grandes factores de la personalidad en estudiantes universitarios de México. (at Dirección General de Difusión Cultural y Divulgación Científica, Ed.) Reportes Técnicos de Investigación ICSA. 2011; 9 (1): 31.

11. Dueñas SC. La cultura de donación de órganos y tejidos en el hospital general de Pachuca, Hidalgo. Universidad Autónoma del Estado de Hidalgo. Instituto de Ciencias Sociales y Humanidades. 2005.
12. Zepeda-Romero LC, García-García G, Aguirre-Jaúregui O. Resultados de una encuesta sobre donación y trasplante de órganos en la zona metropolitana de Guadalajara, México. Salud Pública de México. 2003; 45 (1): 54-57.

13. Zambudio AR, Conesa C, Ramírez P, Galindo PJ, Martínez $\mathrm{L}$, Rodríguez MM, Parrilla P. What is the attitude of hospital transplant-related personnel toward donation? The Journal of heart and lung transplantation, 2006; 25 (8): 972-976.

14. Cuende N, Canon JF, Alonso M, Delagebasala CM, Sagredo E, Miranda B. Quality assurance program in the process of donation and transplantation at the National Organization of Transplantations. Nefrologia.2001; 21: 65-76.

15. López VR. La donación de órganos en México a través del consentimiento presunto: de las cifras a la inacción y la ética. Centro de Estudios Sociales y de Opinión Publica. 2018, 277.

16. Salazar GJM. Donar es Perdurar. Una visión ética, histórica y médica. CienciaUAT. 2008; 3 (1): 40-44.

17. Vélez EV. Donación de órganos, una perspectiva antropológica. Enfermería Nefrológica. 2007; 10 (3): 179-184.

18. Dib-Kuri A, Aburto-Morales S, Espinosa-Álvarez A, SánchezRamírez O. Trasplantes de órganos y tejidos en México. Rev Invest Clin. 2005; 57 (2): 163-169.

19. González AM, García JM, Manrique S. Donación de órganos para trasplantes. Aspectos psicosociales. Nefrología. 1991; 11: 62-68.

20. Guerra Carrasco R. Donación de órganos: comprensión y significado. 2005.

21. San Gregorio MP, Roldán JD, Cabezas FM, Roldan AN. Factores sociales y psicológicos que influyen en la donación de órganos. Psicothema. 1993; 5 (2): 241-253.

22. Miedes AC, Sancho MM. Variables influyentes en la actitud hacia la donación de órganos. Psicothema. 2000; 12 (Suplemento): 100-102.

23. Ghorbani F, Khoddami-Vishteh HR, Ghobadi O, Shafaghi S, Louyeh AR, Najafizadeh K. Causes of family refusal for organ donation. Transplant Proc. 2011; 43 (2): 405-406.

24. Weber FR, Batalla IM. Encuesta de opinión sobre la donación de órganos. Acta Médica Grupo Ángeles. 2004; 2 (1): 7-12.

25. Organización Mundial de la Salud, "Trasplante de órganos y tejidos humanos", Organización Mundial de la salud. [Consulta Octubre 2019] Disponible en: http://apps.who.int/iris/ bitstream/10665/26197/1/B123_5-sp.pdf?ua=1

26. Instituto Nacional de Estadística y Geografía Puebla. [Consulta Noviembre 2019] Disponible en: https://www.inegi.org.mx/app/ areasgeograficas/?ag $=21$

27. Martinez JM, Martin A, López JS. Spanish public opinion concerning organ donation and transplantation. Medicina Clínica. 1995; 105 (11): 401-406.

28. Cheung AS, Alden DL, Wheeler MS. Cultural attitudes of AsianAmericans toward death adversely impact organ donation. Transplant Proc. 1998; 30 (7): 3609-3610.

29. Aguilar-Barojas S. Fórmulas para el cálculo de la muestra en investigaciones de salud. Salud en Tabasco. 2005; 11 (1-2): 333-333.

30. México. Diagnóstico de muerte encefálica y manejo del potencial donante de órganos. Guía de Práctica Clínica: Evidencias y Recomendaciones. México, CENETEC; 2019. [Consulta 12 Febrero 2020] Disponible en: http://www.cenetec. salud.gob.mx/descargas/gpc/CatalogoMaestro/488GPC_ DxMuerteCncefxlica/G PC_Muerte_Encefaxlica.pdf.

Correspondencia:

Ana Karen Ruiz-Dionisio

E-mail: ann.ruiz16@outlook.com 